Article

\title{
Synthesis, and Antitumor Activity of Some N1-(Coumarin-7-yl) Amidrazones and Related Congeners
}

\author{
Mohammad S. Mustafa ${ }^{1}$, Mustafa M. El-Abadelah ${ }^{1}$, Malek A. Zihlif ${ }^{2}$, Randa G. Naffa ${ }^{3}$ and
} Mohammad S. Mubarak ${ }^{1, *}$

1 Department of Chemistry, The University of Jordan, Amman 11942, Jordan

2 Department of Pharmacology, Faculty of Medicine, The University of Jordan, Amman 11942, Jordan

3 Molecular Biology Research Laboratory, Faculty of Medicine, The University of Jordan, Amman 11942, Jordan

* Author to whom correspondence should be addressed; E-Mail: mmubarak@ju.edu.jo;

Tel.: +96-26-535-5000 Ext. 22021; Fax: +96-26-530-0253.

Received: 8 April 2011; in revised form: 9 May 2011 / Accepted: 11 May 2011 /

Published: 24 May 2011

Abstract: A series of new N1-(coumarin-7-yl)amidrazones incorporating $N$-piperazines and related congeners were synthesized by reacting the hydrazonoyl chloride derived from 7-amino-4-methylcoumarin with the appropriate piperazines. The chemical structures of the newly prepared compounds were supported by elemental analyses, ${ }^{1} \mathrm{H}-\mathrm{NMR}$, ${ }^{13} \mathrm{C}-\mathrm{NMR}$, and ESI-HRMS spectral data. The antitumor activity of the newly synthesized compounds was evaluated. Among all the compounds tested, 7-\{2-[1-(4-(1-benzyl-2-ethyl4-nitro-1H-imidazol-5-yl)piperazin-1-yl)-2-oxopropylidene]hydrazinyl $\}$-4-methyl-2Hchromen-2-one (3n) was the most potent against MCF-7 and $\mathrm{K} 562$ cells, with $\mathrm{IC}_{50}$ values of 20.2 and $9.3 \mu \mathrm{M}$, respectively.

Keywords: 7-aminocoumarins; $N$-(coumarin-7-yl)hydrazonoyl chloride; 1-piperazinyl amidrazones; nitrileimine; antitumor activity 


\section{Introduction}

Due to their structural and therapeutic diversity as pharmaceutical agents, along with their commercial availability, piperazine derivatives continue to capture the attention of synthetic and medicinal chemists. Piperazine-based compounds have been employed as antibacterial, antidepressant, and antitumor drugs, and as $\alpha$-adrenoceptor antagonists, CCR5 receptor antagonists, 5-HT7 receptor antagonists, and adenosine A2a receptor antagonists [1]. Several piperazine derivatives have reached the stage of clinical application; among the known drugs that are used to treat anxiety is a pyrimidinyl piperazinyl compound (buspirone, BuSpar $^{\circledR}$ ) [2], while a 3-chlorophenyl piperazinyl drug (trazodone, Desyrel ${ }^{\circledR}$ ) is used as an antidepressant [3]. Besides, several publications have dealt with the synthesis and evaluation of thrombin inhibitors that incorporate an amidrazone functionality as a structural motif [4-6], and there is a report pertaining to the inactivation of lipoxygenase-1 from soybeans by open-chain and cyclic amidrazones [7].

On the other hand, coumarin derivatives have drawn considerable attention from researchers due to their role in natural and synthetic organic chemistry, and their interesting biological activities. Compounds which contain a coumarin nucleus were found to exhibit various biological activities such as anticoagulant and antithrombotic properties [8]. Some derivatives have shown molluscicidal, anthelmintic [9], hypnotic, and insecticidal [10] activity, while others have served as antifungal [11], anti-inflammatory [12] and antiviral agents, including against human immunodeficiency virus [13], and anticoagulant properties [14]. In addition, coumarins have also been used as additives in food and cosmetics [15], and in the preparation of optical brighteners, dispersed fluorescent and laser dyes [16].

In view of the widespread interest in the activity spectrum and profile of coumarins [17-20], and in continuation of our work on the synthesis of new compounds of pharmacological and biological interest [1,21-24], we describe herein the preparation and spectroscopic characterization of some new piperazinyl amidrazones containing coumarin moieties and evaluation of their antitumor activity.

\section{Results and Discussion}

\subsection{Chemistry}

The hydrazonoyl chloride synthon 2 required in this study is prepared via direct coupling of 4-methylcoumarin-7-diazonium chloride with 3-chloropentane-2,4-dione in aqueous-ethanolic sodium acetate (Japp-Klingemann reaction) [25-27] (Scheme 1). An acidic solution of the former coumarin-7diazonium chloride is freshly prepared by diazotization of 7-amino-4-methylcoumarin (suspended in $6 \mathrm{~N}$ aq. $\mathrm{HCl}$ ) which, in turn, is prepared from $m$-aminophenol according to a reported procedure [28-29].

Piperazine, $N$-substituted piperazines and related cyclic secondary amine congeners, acting as nitrogen nucleophiles, are expected to add readily to $N$-(4-methylcoumarin-7-yl)nitrile imine (the reactive 1,3-dipolar species generated in situ from the corresponding hydrazonoyl chloride precursor 2 in the presence of triethylamine) to give the respective amidrazone adducts 3a-n (Scheme 2). This mode of nucleophilic addition reaction of various nucleophiles to 1,3-dipoles is well-documented [30-38] and several adducts related to $\mathbf{3}$ were obtained from the reaction of amines with hydrazonoyl chlorides. 
Scheme 1. Synthesis of $N$-(4-methyl-2-oxo-2H-chromen-7-yl)-2-oxopropanehydrazonoyl chloride (2).

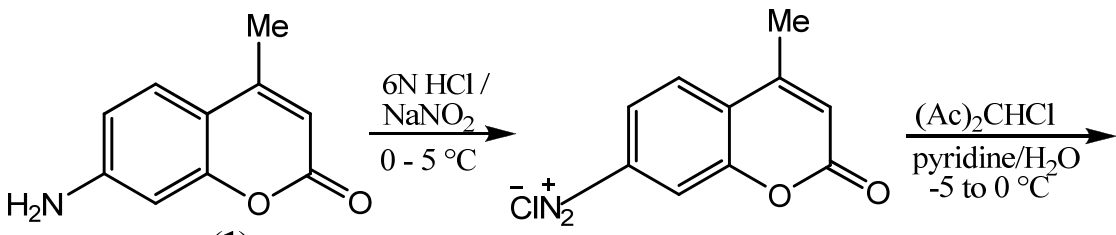

(1)<smiles>Cc1cc(=O)oc2cc(N=NC(Cl)(Cl)C(Cl)(Cl)Cl)ccc12</smiles>

Scheme 2. Synthesis of 4-methyl-7-\{2-[2-oxo-1-(substituted N-hexahydroazinyl)propylidene]hydrazinyl $\}-2 H$-chromen-2-ones 3a-n.

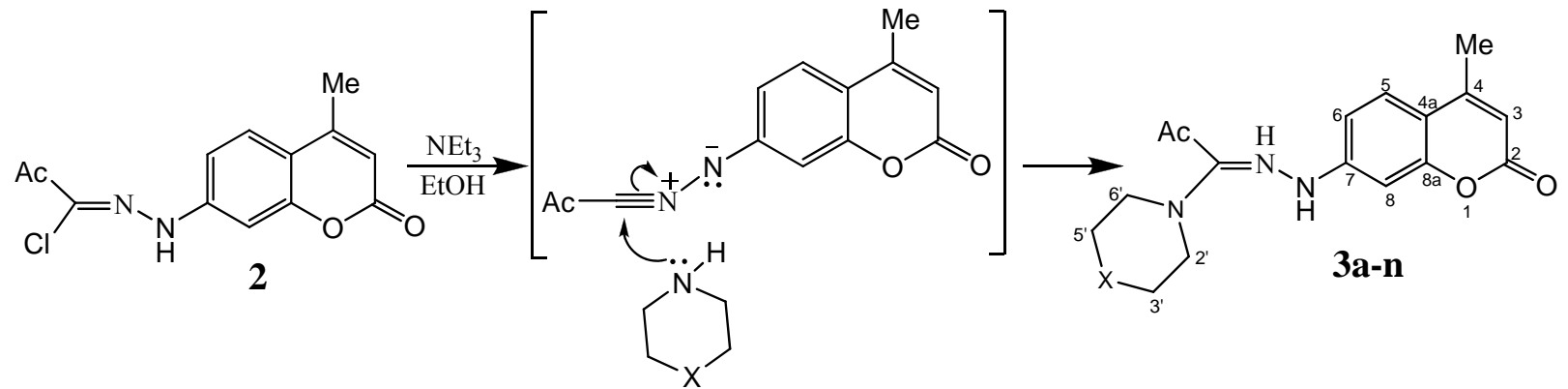
compounds 3a-j

\begin{tabular}{|l|l|l|l|c|c|c|c|c|c|c|}
\hline entry & $\mathbf{a}$ & $\mathbf{b}$ & $\mathbf{c}$ & $\mathbf{d}$ & $\mathbf{e}$ & $\mathbf{f}$ & $\mathbf{g}$ & $\mathbf{h}$ & $\mathbf{i}$ & $\mathbf{j}$ \\
\hline $\mathrm{X}$ & $\mathrm{CH}_{2}$ & $\mathrm{O}$ & $\mathrm{S}$ & $N-\mathrm{H}$ & $N-\mathrm{Me}$ & $N-\mathrm{Et}$ & $N-\mathrm{Pr}$ & $N-\mathrm{Bz}$ & $N-\mathrm{CO}_{2} \mathrm{Et}$ & $N-\mathrm{C}_{2} \mathrm{H}_{4} \mathrm{OH}$ \\
\hline
\end{tabular}

compounds 3k-n $(\mathrm{X}=N$-Ar $)$

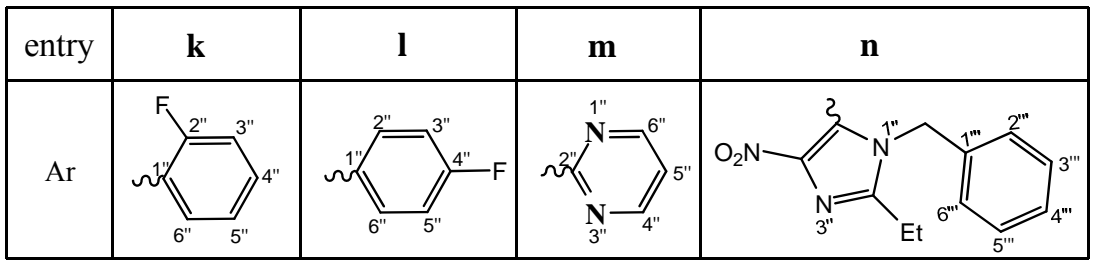

The newly synthesized compounds 3a-n were characterized by elemental analyses, MS and NMR spectral data. These data, detailed in the experimental part, are consistent with the suggested structures. Thus, the mass spectra display the correct molecular ion peaks for which the measured high resolution (HRMS) data are in good agreement with the calculated values. DEPT and 2D (COSY, HMQC, HMBC) experiments showed correlations that helped in the ${ }^{1} \mathrm{H}$ - and ${ }^{13} \mathrm{C}$-signal assignments to the different carbons and their attached, and/or neighboring hydrogens. 


\subsection{Antitumor Activity}

The antitumor activities of compounds 3c-n were characterized by conducting cell viability assays using tetrazolium dye 3-(4,5-dimethylthiazol-2-yl)-2,5-diphenyltetrazolium bromide (MTT). Cultures of MCF7 breast cancer cells and K562 human leukemia cells were treated first at one concentration of $50 \mu \mathrm{g} / \mathrm{mL}$ and the results are shown in Table 1 .

Table 1. Percentage cell survival of MCF-7 and K562 cells following 72 hours exposure to $50 \mu \mathrm{M}$ f all compounds.

\begin{tabular}{ccc}
\hline Compound & $\begin{array}{c}\text { MCF-7 } \\
\text { \% survival } \pm \\
\text { standard deviation }\end{array}$ & $\begin{array}{c}\text { K562 } \\
\text { \% survival } \pm \\
\text { standard deviation }\end{array}$ \\
\hline 3a & $81.8 \pm 4.8$ & $84.1 \pm 3.8$ \\
3b & $81.7 \pm 10.6$ & $82.3 \pm 4.4$ \\
3c & $89.8 \pm 13.7$ & $94.3 \pm 6.3$ \\
3d & $86.4 \pm 5.8$ & $72.7 \pm 1.5$ \\
3e & $89.7 \pm 8.9$ & $85.3 \pm 3.0$ \\
3f & $91.4 \pm 5.9$ & $90.7 \pm 2.3$ \\
3g & $81.5 \pm 4.7$ & $91.1 \pm 3.5$ \\
3h & $80.6 \pm 1.6$ & $89.6 \pm 3.1$ \\
3i & $46.8 \pm 3.5$ & $92.6 \pm 12.2$ \\
3j & $85.6 \pm 2.8$ & $86.5 \pm 3.6$ \\
3k & $85.9 \pm 6.0$ & $96.4 \pm 12.4$ \\
3l & $84.6 \pm 11.0$ & $93.4 \pm 2.2$ \\
3m & $36.2 \pm 5.7$ & $101.3 \pm 3.0$ \\
3n & $43.3 \pm 5.1$ & $52.7 \pm 6.1$ \\
\hline
\end{tabular}

Compounds $3 \mathbf{i}, 3 \mathbf{m}$ and $3 \mathbf{n}$ showed potential anti-MCF-7activity. These compounds were able to reduce the viability after 72 hours to less than 50\%. With respect to K562 cells, only compound 3n showed considerable inhibition of cell proliferation. Furthermore, we explored the anti-tumor activity for $3 \mathbf{i}, 3 \mathbf{m}$ and $\mathbf{3 n}$ (compounds that showed potential activities) in two more cancer cells: breast cancer cell line ZR-75-1 and leukemia cell line HL60. We determined the $\mathrm{IC}_{50}$ values for compounds 3i, 3m and 3n on ZR-75-1 and HL60 additional cell lines, and on the MCF-7 and K526 cell lines as well (Table 2). Notably, compound 3n was the most potent against MCF-7 cells scoring an $\mathrm{IC}_{50}$ value of $20.2 \mu \mathrm{M}$ and showing a very promising activity against the $\mathrm{K} 562$ cells with an $\mathrm{IC}_{50}$ of $9.3 \mu \mathrm{M}$ (Table 2).

Table 2. Effects of compounds 3i, 3m and 3n on MCF-7, ZR-75-1, K562 and HL60.

\begin{tabular}{ccccc}
\hline Compound & $\mathrm{IC}_{50} \mathrm{MCF}-7(\mu \mathrm{M})$ & $\mathrm{IC}_{50} \mathrm{ZR}-75-1(\mu \mathrm{M})$ & $\mathrm{IC}_{50} \mathrm{~K} 562(\mu \mathrm{M})$ & $\mathrm{IC}_{50} \mathrm{HL60}(\mu \mathrm{M})$ \\
\hline Doxorubicin & $0.31 \pm 0.01$ & $1.0 \pm 0.01$ & $3.54 \pm 0.54$ & $0.09 \pm 0.005$ \\
3i & $47.8 \pm 3.3$ & $>100$ & $>100$ & $>100$ \\
3m & $39.7 \pm 1.7$ & $>100$ & $>100$ & $>100$ \\
3n & $20.2 \pm 3.7$ & $>100$ & $9.2 \pm 2.8$ & $>100$ \\
\hline
\end{tabular}

From the structure-activity relationships point of view, the nature of substituents on the $\mathrm{X}$ position seems to play a critical role for the cytotoxic activity. For example, in case of MCF-7 breast cancer 
cells, compounds 3i, 3m, and 3n with the substituent $\mathrm{N}-\mathrm{CO}_{2} \mathrm{Et}, \mathrm{N}-(2$-pyrimidyl), and $\mathrm{N}$-(1-benzyl-2-ethyl4-nitroimidazol-5-yl) appendages, respectively, exhibited cytotoxic $\mathrm{IC}_{50}$ values of 49, 38, and $20 \mu \mathrm{M}$. The shared characteristic feature between these three substituents, which are absent in all others, is the presence of the nucleophilic component next to position X. However, this belief cannot be generalized on the in anti-K562 cell activity, where compound 3n was the only active compound and no activity could be observed with compounds $3 \mathbf{i}$ and $\mathbf{3 m}$. What make compound $\mathbf{3 n}$ active against K562 cells, giving a relatively low $\mathrm{IC}_{50}$ of $9 \mu \mathrm{M}$, may be linked with the bulky substituent that characterized this compound from all others tested. This bulky substituent on compound 3n may also be associated with the lowest $\mathrm{IC}_{50}$ value as exhibited by this compound against the MCF-7 cells.

\section{Experimental}

\subsection{General}

The following chemicals, used in this study, were purchased from Acros and were used as received: piperidine, morpholine, thiomorpholine, piperazine, $N$-alkylpiperazines, $N$-arylpiperazines, ethyl $\mathrm{N}$-piperazinecarboxylate. 1-(1-Benzyl-2-ethyl-4-nitro-1H-imidazol-5-yl)piperazine was prepared according to a literature procedure [39]. Silica-gel for column chromatography was purchased from Macherey-Nagel GmbH \& Co (Germany). Melting points (uncorrected) were determined on a Stuart scientific melting point apparatus in open capillary tubes. ${ }^{1} \mathrm{H}$ - and ${ }^{13} \mathrm{C}-\mathrm{NMR}$ spectra were recorded on a $300 \mathrm{MHz}$ spectrometer (Bruker DPX-300) with TMS as the internal standard. Chemical shifts are expressed in $\delta$ units; $J$-values for ${ }^{1} \mathrm{H}-{ }^{1} \mathrm{H},{ }^{1} \mathrm{H}-\mathrm{F}$ and ${ }^{13} \mathrm{C}$-F coupling constants are given in Hertz. High resolution mass spectra (HRMS) were acquired (in positive or negative mode) using electrospray ion trap (ESI) technique by collision-induced dissociation on a Bruker APEX-4 (7-Tesla) instrument. The samples were dissolved in acetonitrile, diluted in spray solution (methanol/water $1: 1 \mathrm{v} / \mathrm{v}+0.1 \%$ formic acid) and infused using a syringe pump with a flow rate of $2 \mu \mathrm{L} / \mathrm{min}$. External calibration was conducted using arginine cluster in a mass range $m / z$ 175-871.

\subsection{7-Amino-4-methylcoumarin (1)}

This synthon, required in the present study, was prepared according to a literature procedure [28-29] which involves reaction of $m$-aminophenol with methoxycarbonyl chloride as the initial step; the resulting $\mathrm{N}$-protected $\mathrm{m}$-aminophenol underwent cyclocondensation upon reaction with ethyl acetoacetate and conc. sulpuric acid, followed by removal of the $N$-protecting group (via treatment with sodium hydroxide) to deliver the title compound $1 ; \mathrm{mp}=224-226^{\circ} \mathrm{C}$ (lit. $\mathrm{mp}=226-227^{\circ} \mathrm{C}$ ) [28-29].

\subsection{N-(4-Methyl-2-oxo-2H-chromen-7-yl)-2-oxo-propanehydrazonoyl chloride (2)}

Compound 1 (17.5 g, $0.10 \mathrm{~mol})$ was dissolved in $17 \%$ aqueous hydrochloric acid $(160 \mathrm{~mL})$. To this solution was added drop-wise a solution of sodium nitrite $(7.6 \mathrm{~g}, 0.11 \mathrm{~mol})$ in water $(15 \mathrm{~mL})$ with efficient stirring at 0-5 ${ }^{\circ} \mathrm{C}$. Stirring was continued for 20-30 min., and the resulting fresh cold 4-methyl-2-oxo-2H-chromene-7-diazonium chloride [also named as 7-(chlorodiazenyl)-4-methylcoumarin] solution was poured onto cold solution ( 0 to $-10{ }^{\circ} \mathrm{C}$, ice-salt bath) of 3-chloropentan-2,4dione $(13.5 \mathrm{~g}, 0.1 \mathrm{~mol})$ in ethanol/water $(160 \mathrm{~mL}, 1: 1 \mathrm{v} / \mathrm{v})$ containing $30.0 \mathrm{~g}$ of sodium acetate with 
vigorous stirring. The resulting yellowish-colored mixture was further stirred until a solid precipitate was formed (5-10 min). The reaction mixture was then diluted with cold water $(200 \mathrm{~mL})$, the solid product was collected by suction filtration, washed several times with cold water, dried, and recrystallized from acetonitrile. Yield $25.4 \mathrm{~g}(91 \%) ; \mathrm{Mp}=271-274{ }^{\circ} \mathrm{C} .{ }^{1} \mathrm{H}-\mathrm{NMR}\left(300 \mathrm{MHz}, \mathrm{DMSO}-\mathrm{d}_{6}\right)$ : $\delta=2.34\left(\mathrm{~d}, J=1.0 \mathrm{~Hz}, 3 \mathrm{H}, \mathrm{CH}_{3}-4\right), 2.46\left(\mathrm{~s}, 3 \mathrm{H}, \mathrm{O}=\mathrm{C}-\mathrm{CH}_{3}\right), 6.17(\mathrm{~d}, J=1.0 \mathrm{~Hz}, 1 \mathrm{H}, \mathrm{H}-3), 7.27$ (d, $J=1.8 \mathrm{~Hz}, 1 \mathrm{H}, \mathrm{H}-8), 7.38$ (dd, $J=8.7,1.8 \mathrm{~Hz}, 1 \mathrm{H}, \mathrm{H}-6), 7.67$ (d, $J=8.7 \mathrm{~Hz}, 1 \mathrm{H}, \mathrm{H}-5), 10.97$ (s, 1H, $\mathrm{N}-\mathrm{H}) .{ }^{13} \mathrm{C}-\mathrm{NMR}\left(75 \mathrm{MHz}, \mathrm{DMSO}-\mathrm{d}_{6}\right): \delta=18.6\left(\mathrm{CH}_{3}-4\right), 26.0\left(\mathrm{O}=\mathrm{C}-\mathrm{CH}_{3}\right), 101.9(\mathrm{C}-8), 111.8(\mathrm{C}-6)$, 112.1 (C-3), 115.1 (C-4a), 127.1 (C-5), 146.0 (C-4), 146.2 (C-7), 153.8 (-C=N), 154.9 (C-8a), 160.5 (C-2), $188.6(\mathrm{O}=\mathrm{C}-\mathrm{Me})$. Anal. Calcd. for $\mathrm{C}_{13} \mathrm{H}_{11} \mathrm{ClN}_{2} \mathrm{O}_{3}$ (278.69 g/mol): C, 56.03; H, 3.98; Cl, 12.72; $\mathrm{N}, 10.05$. Found: C, 56.18; H, 4.05; Cl, 12.56; N, 9.93. ESI-HRMS m/z: Calcd. for $\mathrm{C}_{13} \mathrm{H}_{12} \mathrm{ClN}_{2} \mathrm{O}_{3}$ $[\mathrm{M}+\mathrm{H}]^{+}$279.05364. Found: 279.05310 .

3.4. General procedure for the preparation of 4-Methyl-7-\{2-[2-oxo-1-(substituted N-hexahydroazinyl)propylidene] hydrazinyl\}-2H-chromen-2-ones 3a-n

To a cold suspension $\left(0\right.$ to $\left.-10^{\circ} \mathrm{C}\right)$ of compound $2(0.5 \mathrm{~g}, 1.8 \mathrm{mmol})$ in ethanol $(20 \mathrm{~mL})$ was added, with stirring, a solution of the appropriate secondary amine $(2.0 \mathrm{mmol})$ and triethylamine $(3 \mathrm{~mL}) \mathrm{in}$ ethanol $(10 \mathrm{~mL})$. Stirring was continued at $0-5{ }^{\circ} \mathrm{C}$ for $2-4 \mathrm{~h}$, and then at ambient temperature for $10-12 \mathrm{~h}$. The solvent was then removed under reduce pressure and the residue was treated with water $(15 \mathrm{~mL})$. The resulting crude solid product was collected by suction filtration, washed with water, dried and purified on preparative silica gel TLC plates.

4-Methyl-7-\{2-[2-oxo-1-(piperidin-1-yl)propylidene]hydrazinyl $\}-2 H$-chromen-2-one (3a): Yield = $0.45 \mathrm{~g}$ (76.8\%); $\mathrm{Mp}=190-192{ }^{\circ} \mathrm{C} .{ }^{1} \mathrm{H}-\mathrm{NMR} \quad\left(300 \mathrm{MHz}, \quad\right.$ DMSO-d $\left.\mathrm{d}_{6}\right): \delta=1.50(\mathrm{~m}, \quad 2 \mathrm{H}$, $\left.\mathrm{H}_{2}-4^{\prime}\right), 1.63$ (m, 4H, H $\left.{ }_{2}-3^{\prime}+\mathrm{H}_{2}-5^{\prime}\right), 2.34$ (d, J = $\left.1.0 \mathrm{~Hz}, 3 \mathrm{H}, \mathrm{CH}_{3}-4\right), 2.35$ (s, 3H, O=C-CH3), 2.89 (m, $4 \mathrm{H}, \mathrm{H}_{2}-2^{\prime}+\mathrm{H}_{2}-6^{\prime}$ ), 6.11 (d, J=1.0 Hz, 1H, H-3), 7.25 (d, J=2.0 Hz, 1H, H-8), 7.34 (dd, J = 8.7, $2.0 \mathrm{~Hz}$, 1H, H-6), 7.65 (d, $J=8.7 \mathrm{~Hz}, 1 \mathrm{H}, \mathrm{H}-5), 9.83$ (s, 1H, N-H). ${ }^{13} \mathrm{C}-\mathrm{NMR}\left(75 \mathrm{MHz}, \mathrm{DMSO}-\mathrm{d}_{6}\right): \delta=18.5$ $\left(\mathrm{CH}_{3}-4\right), 24.4\left(\mathrm{C}-4^{\prime}\right), 25.7\left(\mathrm{C}-3^{\prime} / \mathrm{C}-5^{\prime}\right), 26.6\left(\mathrm{O}=\mathrm{C}-\mathrm{CH}_{3}\right), 49.1\left(\mathrm{C}-2^{\prime} / \mathrm{C}-6^{\prime}\right), 100.9(\mathrm{C}-8), 111.6(\mathrm{C}-6)$, 111.1 (C-3), 113.8 (C-4a), 126.8 (C-5), 146.0 (C-4), 147.4 (C-7), 153.9 (-C=N), 155.1 (C-8a), 160.7 (C-2), $195.5(\mathrm{O}=\mathrm{C}-\mathrm{Me})$. Anal. Calcd. for $\mathrm{C}_{18} \mathrm{H}_{21} \mathrm{~N}_{3} \mathrm{O}_{3}(327.38 \mathrm{~g} / \mathrm{mol})$ : C, 66.04; H, 6.47; N, 12.84 . Found: C, 65.88; H, 6.41; N, 12.72. ESI-HRMS m/z: Calcd. for $\mathrm{C}_{18} \mathrm{H}_{20} \mathrm{~N}_{3} \mathrm{O}_{3}[\mathrm{M}-\mathrm{H}]^{-} 326.15047$. Found: 326.14992 .

4-Methyl-7-\{2-[1-morpholino-2-oxopropylidene]hydrazinyl\}-2H-chromen-2-one (3b): Yield = $0.41 \mathrm{~g}$ (69.2\%); $\mathrm{Mp}=213-215^{\circ} \mathrm{C} .{ }^{1} \mathrm{H}-\mathrm{NMR}\left(300 \mathrm{MHz}, \mathrm{CDCl}_{3}\right): \delta=2.39\left(\mathrm{~d}, J=1.0 \mathrm{~Hz}, 3 \mathrm{H}, \mathrm{CH}_{3}-4\right), 2.42$ (s, $\left.3 \mathrm{H}, \mathrm{O}=\mathrm{C}-\mathrm{CH}_{3}\right), 3.07\left(\mathrm{~m}, 4 \mathrm{H}, \mathrm{H}_{2}-2^{\prime}+\mathrm{H}_{2}-6^{\prime}\right), 3.80\left(\mathrm{~m}, 4 \mathrm{H}, \mathrm{H}_{2}-3^{\prime}+\mathrm{H}_{2}-5^{\prime}\right), 6.12(\mathrm{~d}, J=1.0 \mathrm{~Hz}, 1 \mathrm{H}, \mathrm{H}-$ 3), $7.06(\mathrm{dd}, J=8.7,2.0 \mathrm{~Hz}, 1 \mathrm{H}, \mathrm{H}-6), 7.19(\mathrm{~d}, J=2.0 \mathrm{~Hz}, 1 \mathrm{H}, \mathrm{H}-8), 7.51$ (d, $J=8.7 \mathrm{~Hz}, 1 \mathrm{H}, \mathrm{H}-5), 9.32(\mathrm{~s}, 1 \mathrm{H}, \mathrm{N}-\mathrm{H}) .{ }^{13} \mathrm{C}-\mathrm{NMR}\left(75 \mathrm{MHz}, \mathrm{CDCl}_{3}\right): \delta=18.5\left(\mathrm{CH}_{3}-4\right), 26.6$ $\left(\mathrm{O}=\mathrm{C}-\mathrm{CH}_{3}\right), 66.5\left(\mathrm{C}-3^{\prime} / \mathrm{C}-5^{\prime}\right), 48.2\left(\mathrm{C}-2^{\prime} / \mathrm{C}-6^{\prime}\right), 101.2(\mathrm{C}-8), 111.3$ (C-6), 111.7 (C-3), $113.9(\mathrm{C}-4 \mathrm{a})$, 126.8 (C-5), 144.3 (C-4), 147.3 (C-7), 153.8 (-C=N), 155.1 (C-8a), 160.7 (C-2), 195.3 (O=C-Me). Anal. Calcd for $\mathrm{C}_{17} \mathrm{H}_{19} \mathrm{~N}_{3} \mathrm{O}_{4}(329.35 \mathrm{~g} / \mathrm{mol})$ : C, 62.00; H, 5.81; N, 12.76. Found: C, 62.14; H, 5.78; N, 12.65. ESI-HRMS m/z: Calcd for $\mathrm{C}_{17} \mathrm{H}_{18} \mathrm{~N}_{3} \mathrm{O}_{4}[\mathrm{M}-\mathrm{H}]^{-}$328.12973. Found: 328.12925. 
4-Methyl-7-\{2-[2-oxo-1-thiomorpholinopropylidene]hydrazinyl $\}-2 H$-chromen-2-one (3c): Yield $=0.45 \mathrm{~g}$ (72.4\%); $\mathrm{Mp}=236-238^{\circ} \mathrm{C} .{ }^{1} \mathrm{H}-\mathrm{NMR}\left(300 \mathrm{MHz}, \mathrm{CDCl}_{3}\right): \delta=2.39\left(\mathrm{~d}, J=1.0 \mathrm{~Hz}, 3 \mathrm{H}, \mathrm{CH}_{3}-4\right), 2.41$ (s, $\left.3 \mathrm{H}, \mathrm{O}=\mathrm{C}-\mathrm{CH}_{3}\right), 2.75\left(\mathrm{~m}, 4 \mathrm{H}, \mathrm{H}_{2}-3^{\prime}+\mathrm{H}_{2}-5^{\prime}\right), 3.26\left(\mathrm{~m}, 4 \mathrm{H}, \mathrm{H}_{2}-2^{\prime}+\mathrm{H}_{2}-6^{\prime}\right), 6.14(\mathrm{~d}, J=1.0 \mathrm{~Hz}, 1 \mathrm{H}, \mathrm{H}-3)$, $7.03(\mathrm{dd}, J=8.7,2.0 \mathrm{~Hz}, 1 \mathrm{H}, \mathrm{H}-6), 7.18(\mathrm{~d}, J=2.0 \mathrm{~Hz}, 1 \mathrm{H}, \mathrm{H}-8), 7.52(\mathrm{~d}$, $J=8.7 \mathrm{~Hz}, 1 \mathrm{H}, \mathrm{H}-5), 9.12(\mathrm{~s}, 1 \mathrm{H}, \mathrm{N}-\mathrm{H}) .{ }^{13} \mathrm{C}-\mathrm{NMR}\left(75 \mathrm{MHz}, \mathrm{CDCl}_{3}\right): \delta=18.7\left(\mathrm{CH}_{3}-4\right), 25.9$ $\left(\mathrm{O}=\mathrm{C}-\mathrm{CH}_{3}\right), 28.5\left(\mathrm{C}-3^{\prime} / \mathrm{C}-5^{\prime}\right), 50.3\left(\mathrm{C}-2^{\prime} / \mathrm{C}-6^{\prime}\right), 101.6(\mathrm{C}-8), 110.7$ (C-6), 112.3 (C-3), 114.7 (C-4a), 125.9 (C-5), 145.4 (C-4), 145.6 (C-7), 152.5 (-C=N), 155.3 (C-8a), 161.2 (C-2), 195.0 (O=C-Me). Anal. Calcd. for $\mathrm{C}_{17} \mathrm{H}_{19} \mathrm{~N}_{3} \mathrm{O}_{3} \mathrm{~S}$ (345.42 g/mol): C, 59.11; H, 5.54; N, 12.17. Found: C, 58.92; H, 5.51; $\mathrm{N}$, 12.06. ESI-HRMS m/z: Calcd. for $\mathrm{C}_{17} \mathrm{H}_{19} \mathrm{~N}_{3} \mathrm{NaO}_{3} \mathrm{~S}[\mathrm{M}+\mathrm{Na}]^{+}$368.10448. Found: 368.10393.

4-Methyl-7-\{2-[2-oxo-1-(piperazin-1-yl)propylidene] hydrazinyl\}-2H-chromen-2-one (3d): Yield $=0.36 \mathrm{~g}(61 \%) ; \mathrm{Mp}=219-222{ }^{\circ} \mathrm{C} .{ }^{1} \mathrm{H}-\mathrm{NMR}\left(300 \mathrm{MHz}, \mathrm{CDCl}_{3}\right): \delta=1.65\left(\mathrm{~s}, 1 \mathrm{H}, \mathrm{N}\left(4^{\prime}\right)-\mathrm{H}\right), 2.39$ $\left(\mathrm{d}, J=1.0 \mathrm{~Hz}, 3 \mathrm{H}, \mathrm{CH}_{3}-4\right), 2.41\left(\mathrm{~s}, 3 \mathrm{H}, \mathrm{O}=\mathrm{C}-\mathrm{CH}_{3}\right), 2.98\left(\mathrm{~m}, 4 \mathrm{H}, \mathrm{H}_{2}-2^{\prime}+\mathrm{H}_{2}-6^{\prime}\right), 2.99(\mathrm{~m}, 4 \mathrm{H}$, $\left.\mathrm{H}_{2}-3^{\prime}+\mathrm{H}_{2}-5^{\prime}\right), 6.13$ (d, $\left.J=1.0 \mathrm{~Hz}, 1 \mathrm{H}, \mathrm{H}-3\right), 7.04$ (dd, $\left.J=8.7,2.0 \mathrm{~Hz}, 1 \mathrm{H}, \mathrm{H}-6\right), 7.16$ (d, $J=2.0 \mathrm{~Hz}$, $1 \mathrm{H}, \mathrm{H}-8), 7.51(\mathrm{~d}, J=8.7 \mathrm{~Hz}, 1 \mathrm{H}, \mathrm{H}-5), 9.29(\mathrm{~s}, 1 \mathrm{H}, \mathrm{N}-\mathrm{H}) \cdot{ }^{13} \mathrm{C}-\mathrm{NMR}\left(75 \mathrm{MHz}, \mathrm{CDCl}_{3}\right): \delta=18.7$ $\left(\mathrm{CH}_{3}-4\right), 26.0\left(\mathrm{O}=\mathrm{C}-\mathrm{CH}_{3}\right), 46.6\left(\mathrm{C}-3^{\prime} / \mathrm{C}-5^{\prime}\right), 49.3\left(\mathrm{C}-2^{\prime} / \mathrm{C}-6^{\prime}\right), 101.5$ (C-8), 110.7 (C-6), 112.1 (C-3), 114.5 (C-4a), 125.9 (C-5), 145.0 (C-4), 145.7 (C-7), $152.5(-\mathrm{C}=\mathrm{N}), 155.3$ (C-8a), 161.3 (C-2), 195.2 $(\mathrm{O}=\mathrm{C}-\mathrm{Me})$. Anal. Calcd. for $\mathrm{C}_{17} \mathrm{H}_{20} \mathrm{~N}_{4} \mathrm{O}_{3}(328.37 \mathrm{~g} / \mathrm{mol})$ : $\mathrm{C}, 62.18 ; \mathrm{H}, 6.14 ; \mathrm{N}, 17.06$. Found: $\mathrm{C}, 62.04$; $\mathrm{H}, 6.08$; N, 16.92. ESI-HRMS m/z: Calcd. for $\mathrm{C}_{17} \mathrm{H}_{21} \mathrm{~N}_{4} \mathrm{O}_{3}[\mathrm{M}+\mathrm{H}]^{+}$329.16137. Found: 329.16083 .

4-Methyl-7-\{2-[1-(4-methylpiperazin-1-yl)-2-oxo-propylidene]hydrazinyl\}-2H-chromen-2-one (3e): Yield $=0.50 \mathrm{~g}(81.2 \%) ; \mathrm{Mp}=182-183{ }^{\circ} \mathrm{C} .{ }^{1} \mathrm{H}-\mathrm{NMR}\left(300 \mathrm{MHz}, \mathrm{CDCl}_{3}\right): \delta=2.36(\mathrm{~d}, J=1.0 \mathrm{~Hz}, 3 \mathrm{H}$, $\left.\mathrm{CH}_{3}-4\right), 2.40$ (s, 3H, O=C-CH3), 2.43 (s, 3H, N-CH $), 2.63\left(\mathrm{~m}, 4 \mathrm{H}, \mathrm{H}_{2}-3^{\prime}+\mathrm{H}_{2}-5^{\prime}\right), 3.14$ (m, 4H, $\mathrm{H}_{2}-2^{\prime}$ $+\mathrm{H}_{2}-6^{\prime}$ ), 6.12 (d, $\left.J=1.0 \mathrm{~Hz}, 1 \mathrm{H}, \mathrm{H}-3\right), 7.07$ (dd, $\left.J=8.7,2.0 \mathrm{~Hz}, 1 \mathrm{H}, \mathrm{H}-6\right), 7.16$ (d, J = 2.0 Hz, 1H, H8), $7.52(\mathrm{~d}, J=8.7 \mathrm{~Hz}, 1 \mathrm{H}, \mathrm{H}-5), 9.23(\mathrm{~s}, 1 \mathrm{H}, \mathrm{N}-\mathrm{H}) .{ }^{13} \mathrm{C}-\mathrm{NMR}\left(75 \mathrm{MHz}, \mathrm{CDCl}_{3}\right): \delta=18.7$ (C-4), $25.9\left(\mathrm{O}=\mathrm{C}-\mathrm{CH}_{3}\right), 46.4\left(\mathrm{~N}-\mathrm{CH}_{3}\right), 47.9\left(\mathrm{C}-2^{\prime} / \mathrm{C}-6^{\prime}\right), 55.7\left(\mathrm{C}-3^{\prime} / \mathrm{C}-5^{\prime}\right), 101.4(\mathrm{C}-8), 110.7$ (C-6), 112.0 (C-3), 114.4 (C-4a), 125.8 (C-5), 145.0 (C-4), 145.8 (C-7), 152.5 (-C=N), 155.2 (C-8a), 161.2 (C-2), $195.0(\mathrm{O}=\mathrm{C}-\mathrm{Me})$. Anal. Calcd. for $\mathrm{C}_{18} \mathrm{H}_{22} \mathrm{~N}_{4} \mathrm{O}_{3}(342.39 \mathrm{~g} / \mathrm{mol})$ : C, 63.14; H, 6.48; N, 16.36 . Found: C, 63.22; H, 6.51; N, 16.23. ESI-HRMS m/z: Calcd. for $\mathrm{C}_{18} \mathrm{H}_{23} \mathrm{~N}_{4} \mathrm{O}_{3}[\mathrm{M}+\mathrm{H}]^{+} 343.17702$. Found: 343.17652 .

7-\{2-[1-(4-Ethylpiperazin-1-yl)-2-oxopropylidene]hydrazinyl\}4-methyl-2H-chromen-2-one

(3f):

Yield $=0.40 \mathrm{~g}(62.4 \%) ; \mathrm{Mp}=165-168{ }^{\circ} \mathrm{C} .{ }^{1} \mathrm{H}-\mathrm{NMR}\left(300 \mathrm{MHz}, \mathrm{CDCl}_{3}\right): \delta=1.12(\mathrm{t}, J=7.2 \mathrm{~Hz}, 3 \mathrm{H}$, $\left.\mathrm{CH}_{3}-\mathrm{CH}_{2}-\right), 2.50\left(\mathrm{q}, 2 \mathrm{H}, J=7.2 \mathrm{~Hz}, \mathrm{CH}_{3}-\mathrm{CH}_{2}-\mathrm{N}\right), 2.39$ (d, $\left.J=1.0 \mathrm{~Hz}, 3 \mathrm{H}, \mathrm{CH}_{3}-4\right), 2.42(\mathrm{~s}, 3 \mathrm{H}$, $\left.\mathrm{O}=\mathrm{C}-\mathrm{CH}_{3}\right), 2.58\left(\mathrm{~m}, 4 \mathrm{H}, \mathrm{H}_{2}-3^{\prime}+\mathrm{H}_{2}-5^{\prime}\right), 3.11\left(\mathrm{~m}, 4 \mathrm{H}, \mathrm{H}_{2}-2^{\prime}+\mathrm{H}_{2}-6^{\prime}\right), 6.12(\mathrm{~d}, J=1.0 \mathrm{~Hz}, 1 \mathrm{H}, \mathrm{H}-3)$, 7.05 (dd, $J=8.7 \mathrm{~Hz}, 2.0 \mathrm{~Hz}, 1 \mathrm{H}, \mathrm{H}-6), 7.15$ (d, $J=2.0 \mathrm{~Hz}, 1 \mathrm{H}, \mathrm{H}-8), 7.50$ (d, $J=8.7 \mathrm{~Hz}, 1 \mathrm{H}, \mathrm{H}-5)$, $9.19(\mathrm{~s}, 1 \mathrm{H}, \mathrm{N}-\mathrm{H}) .{ }^{13} \mathrm{C}-\mathrm{NMR}\left(75 \mathrm{MHz}, \mathrm{CDCl}_{3}\right): \delta=12.0\left(\mathrm{CH}_{3}-\mathrm{CH}_{2}\right), 18.7\left(\mathrm{CH}_{3}-4\right), 26.0\left(\mathrm{O}=\mathrm{C}-\mathrm{CH}_{3}\right)$, 47.8 (C-2'/C-6'), 53.3 (C-3'/C-5'), $52.5\left(\mathrm{~N}-C H_{2}\right), 101.4(\mathrm{C}-8), 110.7$ (C-6), $112.0(\mathrm{C}-3), 114.5(\mathrm{C}-4 \mathrm{a})$, 125.9 (C-5), 145.0 (C-4), 145.8 (C-7), 152.5 (-C=N), 155.3 (C-8a), 161.3 (C-2), 195.0 (O=C-Me). Anal. Calcd for $\mathrm{C}_{19} \mathrm{H}_{24} \mathrm{~N}_{4} \mathrm{O}_{3}$ (356.42 g/mol): C, 64.03; H, 6.79; N, 15.72. Found: C, 63.86; H, 6.68; N, 15.54. ESI-HRMS m/z: Calcd for $\mathrm{C}_{19} \mathrm{H}_{25} \mathrm{~N}_{4} \mathrm{O}_{3}[\mathrm{M}+\mathrm{H}]^{+}$357.19267. Found: 357.19212 . 
4-Methyl-7-\{2-[2-oxo-1-(4-propylpiperazin-1-yl)propylidene]hydrazinyl\}-2H-chromen-2-one

(3g):

Yield $=0.51 \mathrm{~g}(76.5 \%) ; \mathrm{Mp}=178-181{ }^{\circ} \mathrm{C} .{ }^{1} \mathrm{H}-\mathrm{NMR}\left(300 \mathrm{MHz}, \mathrm{CDCl}_{3}\right): \delta=0.91(\mathrm{t}, J=7.2 \mathrm{~Hz}, 3 \mathrm{H}$, $\mathrm{CH}_{3} \mathrm{CH}_{2^{-}}$), $1.53\left(\mathrm{~m}, 2 \mathrm{H}, \mathrm{MeCH}_{2^{-}}\right), 2.39$ (d, $\left.J=1.0 \mathrm{~Hz}, 3 \mathrm{H}, \mathrm{CH}_{3}-4\right), 2.41$ (s, 3H, O=C-CH $), 2.48$ (t, $\left.J=7.2,2 \mathrm{H}, \mathrm{N}-\mathrm{CH}_{2}-\right), 2.56\left(\mathrm{~m}, 4 \mathrm{H}, \mathrm{H}_{2}-3^{\prime}+\mathrm{H}_{2}-5^{\prime}\right), 3.09$ (m, 4H, $\left.\mathrm{H}_{2}-2^{\prime}+\mathrm{H}_{2}-6^{\prime}\right), 6.11$ (d, J=1.0 Hz, 1H, H-3), 7.04 (dd, $J=8.7 \mathrm{~Hz}, 2.0 \mathrm{~Hz}, 1 \mathrm{H}, \mathrm{H}-6), 7.15$ (d, $J=2.0 \mathrm{~Hz}, 1 \mathrm{H}, \mathrm{H}-8), 7.50$ (d, J=8.7 Hz, $1 \mathrm{H}, \mathrm{H}-5), 9.20(\mathrm{~s}, 1 \mathrm{H}, \mathrm{N}-\mathrm{H}) .{ }^{13} \mathrm{C}-\mathrm{NMR}\left(75 \mathrm{MHz}, \mathrm{CDCl}_{3}\right): \delta=12.0\left(\mathrm{CH}_{3} \mathrm{CH}_{2}-\right), 18.8\left(\mathrm{CH}_{3}-4\right), 20.0$ $\left(\mathrm{MeCH}_{2}-\right), 26.0\left(\mathrm{O}=\mathrm{C}-\mathrm{CH}_{3}\right), 47.9\left(\mathrm{C}-2^{\prime} / \mathrm{C}-6^{\prime}\right), 53.8\left(\mathrm{C}-3^{\prime} / \mathrm{C}-5^{\prime}\right), 60.7\left(\mathrm{~N}^{\prime} \mathrm{CH}_{2}\right), 101.4(\mathrm{C}-8), 110.7$ (C-6), 112.0 (C-3), 114.5 (C-4a), 125.8 (C-5), 145.0 (C-4), 145.8 (C-7), 152.6 (-C=N), 155.3 (C-8a), 161.4 (C-2), $195.2(\mathrm{O}=\mathrm{C}-\mathrm{Me})$. Anal. Calcd. for $\mathrm{C}_{20} \mathrm{H}_{26} \mathrm{~N}_{4} \mathrm{O}_{3}(370.45 \mathrm{~g} / \mathrm{mol}): \mathrm{C}, 64.84 ; \mathrm{H}, 7.07$; N, 15.12. Found: C, 64.63; H, 6.92; N, 15.05. ESI-HRMS m/z: Calcd. for $\mathrm{C}_{20} \mathrm{H}_{27} \mathrm{~N}_{4} \mathrm{O}_{3}[\mathrm{M}+\mathrm{H}]^{+}$ 371.20832. Found: 371.20793.

7-\{2-[1-(4-Benzylpiperazin-1-yl)-2-oxopropylidene] hydrazinyl $\}-4-m e t h y l-2 H$-chromen-2-one (3h): Yield $=0.46 \mathrm{~g}(61.1 \%) ; \mathrm{Mp}=199-201{ }^{\circ} \mathrm{C} .{ }^{1} \mathrm{H}-\mathrm{NMR}\left(300 \mathrm{MHz}, \mathrm{CDCl}_{3}\right): \delta=2.39(\mathrm{~d}, J=1.0 \mathrm{~Hz}, 3 \mathrm{H}$, $\left.\mathrm{CH}_{3}-4\right), 2.41$ (s, 3H, O=C-CH3), 2.55 (m, 4H, H $\left.{ }_{2}-3^{\prime}+\mathrm{H}_{2}-5^{\prime}\right), 3.07$ (m, 4H, $\left.\mathrm{H}_{2}-2^{\prime}+\mathrm{H}_{2}-6^{\prime}\right), 3.57$ (s, 2H, N-CH $\left.2^{-}\right), 6.12$ (d, $\left.J=1.0 \mathrm{~Hz}, 1 \mathrm{H}, \mathrm{H}-3\right), 7.04$ (dd, $\left.J=8.7 \mathrm{~Hz}, 2.0 \mathrm{~Hz}, 1 \mathrm{H}, \mathrm{H}-6\right), 7.15$ (d, J = 2.0 Hz, 1H, H-8), 7.26-7.33 (m, 5H, H-2"/H-3"/H-4"/H-5"/H-6"), 7.50 (d, J = 8.7 Hz, 1H, H-5), 9.19 (s, 1H, $\mathrm{N}-\mathrm{H}) .{ }^{13} \mathrm{C}-\mathrm{NMR}\left(75 \mathrm{MHz}, \mathrm{CDCl}_{3}\right): \delta=18.7\left(\mathrm{CH}_{3}-4\right), 26.0\left(\mathrm{O}=\mathrm{C}-\mathrm{CH}_{3}\right), 48.0\left(\mathrm{C}-2^{\prime} / \mathrm{C}-6{ }^{\prime}\right), 53.7$ (C-3'/C-5'), $63.2\left(\mathrm{~N}-C H_{2}\right), 101.4(\mathrm{C}-8), 110.7$ (C-6), 112.1 (C-3), 114.5 (C-4a), 125.9 (C-5), 127.2 (C-4"), 128.3 (C-2"/C-6"), 129.1 (C-3"/C-5"), 137.9 (C-1"), 145.2 (C-4), 145.8 (C-7), 152.3 (-C=N), 155.3 (C-8a), 161.3 (C-2), $195.1(\mathrm{O}=\mathrm{C}-\mathrm{Me})$. Anal. Calcd. for $\mathrm{C}_{24} \mathrm{H}_{26} \mathrm{~N}_{4} \mathrm{O}_{3}(418.49 \mathrm{~g} / \mathrm{mol}): \mathrm{C}, 68.88 ; \mathrm{H}$, 6.26; N, 13.39. Found: C, 68.96; H, 6.18; N, 13.24. ESI-HRMS m/z: Calcd. for $\mathrm{C}_{24} \mathrm{H}_{25} \mathrm{~N}_{4} \mathrm{O}_{3}[\mathrm{M}-\mathrm{H}]^{-}$ 417.19267. Found: 417.19212.

Ethyl 4-\{1-[2-(4-methyl-2-oxo-2H-chromen-7-yl)hydrazono]-2-oxopropyl $\}$ piperazine-1-carboxylate (3i): Yield $=0.52 \mathrm{~g}(72.2 \%) ; \mathrm{Mp}=221-223{ }^{\circ} \mathrm{C} .{ }^{1} \mathrm{H}-\mathrm{NMR}\left(300 \mathrm{MHz}, \mathrm{CDCl}_{3}\right): \delta=1.26(\mathrm{t}, J=7.1 \mathrm{~Hz}, 3 \mathrm{H}$, $\left.\mathrm{CH}_{3}-\mathrm{CH}_{2}\right), 2.39$ (d, $\left.J=1.0 \mathrm{~Hz}, 3 \mathrm{H}, \mathrm{CH}_{3}-4\right), 2.42\left(\mathrm{~s}, 3 \mathrm{H}, \mathrm{O}=\mathrm{C}-\mathrm{CH}_{3}\right), 3.02\left(\mathrm{~m}, 4 \mathrm{H}, \mathrm{H}_{2}-3^{\prime}+\mathrm{H}_{2}-5^{\prime}\right), 3.58$ (m, 4H, H2-2' $+\mathrm{H}_{2}-6^{\prime}$ ), 4.15 (q, $J=7.1 \mathrm{~Hz}, 2 \mathrm{H}, \mathrm{MeCH}_{2}$ ), 6.13 (d, J=1.0 Hz, 1H, H-3), 7.05 (dd, $J=8.7 \mathrm{~Hz}, 2.0 \mathrm{~Hz}, 1 \mathrm{H}, \mathrm{H}-6), 7.19(\mathrm{~d}, J=2.0 \mathrm{~Hz}, 1 \mathrm{H}, \mathrm{H}-8), 7.50$ (d, $J=8.7 \mathrm{~Hz}, 1 \mathrm{H}, \mathrm{H}-5), 9.27$ (s, 1H, $\mathrm{N}-\mathrm{H}) .{ }^{13} \mathrm{C}-\mathrm{NMR}\left(75 \mathrm{MHz}, \mathrm{CDCl}_{3}\right): \delta=14.7\left(\mathrm{CH}_{3} \mathrm{CH}_{2}-\right), 18.7\left(\mathrm{CH}_{3}-4\right), 25.9\left(\mathrm{O}=\mathrm{C}-\mathrm{CH}_{3}\right), 44.3$ (C-2'/C-6'), 47.9 (C-3'/C-5'), $61.7\left(\mathrm{MeCH}_{2}-\right), 101.6$ (C-8), 110.8 (C-6), 112.3 (C-3), 114.7 (C-4a), 125.9 (C-5), 144.5 (C-4), 145.5 (C-7), $152.5(-\mathrm{C}=\mathrm{N}), 155.3$ (C-8a), $155.5(\mathrm{O}=\mathrm{C}-\mathrm{N}), 161.2(\mathrm{C}-2), 195.1$ $(\mathrm{O}=\mathrm{C}-\mathrm{Me})$. Anal. Calcd. for $\mathrm{C}_{20} \mathrm{H}_{24} \mathrm{~N}_{4} \mathrm{O}_{5}$ (400.43 g/mol): C, 59.99; H, 6.04; N, 13.99. Found: C, 60.12; $\mathrm{H}, 6.01 ; \mathrm{N}, 13.78$. ESI-HRMS m/z: Calcd. for $\mathrm{C}_{20} \mathrm{H}_{23} \mathrm{~N}_{4} \mathrm{O}_{5}[\mathrm{M}-\mathrm{H}]^{-}$399.16684. Found 399.16630.

7-\{2-[1-(4-(2-Hydroxyethyl)piperazin-1-yl)-2-oxopropylidene]hydrazinyl\}-4-methyl-2H-chromen-2-one (3j): Yield $=0.46 \mathrm{~g}(68.1 \%) ; \mathrm{Mp}=159-162{ }^{\circ} \mathrm{C} .{ }^{1} \mathrm{H}-\mathrm{NMR}\left(300 \mathrm{MHz}, \mathrm{CDCl}_{3}\right): \delta=2.39\left(\mathrm{~d}, J=1.0 \mathrm{~Hz}, 3 \mathrm{H}, \mathrm{CH}_{3^{-}}\right.$ 4), $2.42\left(\mathrm{~s}, 3 \mathrm{H}, \mathrm{O}=\mathrm{C}-\mathrm{CH}_{3}\right), 2.61\left(\mathrm{t}, J=5.2 \mathrm{~Hz}, 2 \mathrm{H},-\mathrm{NCH}_{2} \mathrm{CH}_{2} \mathrm{OH}\right), 2.76\left(\mathrm{~m}, 4 \mathrm{H}_{,} \mathrm{H}_{2}-3^{\prime}+\mathrm{H}_{2}-5^{\prime}\right), 3.09$ (m, 4H, $\left.\mathrm{H}_{2}-2^{\prime}+\mathrm{H}_{2}-6^{\prime}\right), 3.63$ (t, $J=5.2 \mathrm{~Hz}, 2 \mathrm{H},-\mathrm{NCH}_{2} \mathrm{CH}_{2} \mathrm{OH}$ ), 6.13 (d, J=1.0 Hz, 1H, H-3), 7.05 (dd, $J=8.7,2.0 \mathrm{~Hz}, 1 \mathrm{H}, \mathrm{H}-6), 7.15$ (d, $J=2.0 \mathrm{~Hz}, 1 \mathrm{H}, \mathrm{H}-8), 7.51$ (d, $J=8.7 \mathrm{~Hz}, 1 \mathrm{H}, \mathrm{H}-5), 9.20$ (s, $1 \mathrm{H}, \mathrm{N}-$ H). ${ }^{13} \mathrm{C}-\mathrm{NMR}\left(75 \mathrm{MHz}, \mathrm{CDCl}_{3}\right): \delta=18.7\left(\mathrm{CH}_{3}-4\right), 25.9\left(\mathrm{O}=\mathrm{C}-\mathrm{CH}_{3}\right), 48.0\left(\mathrm{C}-2^{\prime} / \mathrm{C}-6^{\prime}\right), 53.5\left(\mathrm{C}-3^{\prime} / \mathrm{C}-5^{\prime}\right)$, $57.7\left(-\mathrm{NCH}_{2} \mathrm{CH}_{2} \mathrm{OH}\right), 59.5\left(-\mathrm{NCH}_{2} \mathrm{CH}_{2} \mathrm{OH}\right), 101.6$ (C-8), 110.7 (C-6), 112.2 (C-3), 114.6 (C-4a), 
$125.9 \quad(\mathrm{C}-5), \quad 144.9 \quad(\mathrm{C}-4), \quad 145.7 \quad(\mathrm{C}-7), \quad 152.5 \quad(-\mathrm{C}=\mathrm{N}), \quad 155.3 \quad(\mathrm{C}-8 \mathrm{a}), \quad 161.3 \quad$ (C-2), 195.2 $(\mathrm{O}=\mathrm{C}-\mathrm{Me})$. Anal. Calcd. for $\mathrm{C}_{19} \mathrm{H}_{24} \mathrm{~N}_{4} \mathrm{O}_{4}(372.42 \mathrm{~g} / \mathrm{mol}): \mathrm{C}, 61.28 ; \mathrm{H}, 6.50 ; \mathrm{N}, 15.04$. Found: C, 61.02; $\mathrm{H}, 6.41$; N, 14.88. ESI-HRMS m/z: Calcd. for $\mathrm{C}_{19} \mathrm{H}_{25} \mathrm{~N}_{4} \mathrm{O}_{4}[\mathrm{M}+\mathrm{H}]^{+}$373.18758. Found: 373.18707 .

7-\{2-[1-(4-(2-Fluorophenyl)piperazin-1-yl) -2-oxopropylidene] hydrazinyl\}-4-methyl-2H-chromen-2one (3k): Yield $=0.42 \mathrm{~g}(55.3 \%) ; \mathrm{Mp}=256-258^{\circ} \mathrm{C} .{ }^{1} \mathrm{H}-\mathrm{NMR}\left(300 \mathrm{MHz}, \mathrm{CDCl}_{3}\right): \delta=2.36(\mathrm{~d}, \mathrm{~J}=1.0 \mathrm{~Hz}$, $\left.3 \mathrm{H}, \mathrm{CH}_{3}-4\right), 2.44$ (s, 3H, O=C-CH3), $3.21\left(\mathrm{~m}, 4 \mathrm{H}, \mathrm{H}_{2}-3^{\prime}+\mathrm{H}_{2}-5^{\prime}\right), 3.24\left(\mathrm{~m}, 4 \mathrm{H}, \mathrm{H}_{2}-2^{\prime}+\mathrm{H}_{2}-6^{\prime}\right), 6.13$ (d, $J=1.0 \mathrm{~Hz}, 1 \mathrm{H}, \mathrm{H}-3), 6.95-7.00$ (m, 4H, H-3" + H-4" + H-5" + H-6"), 7.05 (dd, J=8.7 Hz, 2.1 Hz, 1H, H-6), 7.18 (d, $J=2.1 \mathrm{~Hz}, 1 \mathrm{H}, \mathrm{H}-8), 7.51$ (d, $J=8.7 \mathrm{~Hz}, 1 \mathrm{H}, \mathrm{H}-5), 9.25$ (s, 1H, N-H). ${ }^{13} \mathrm{C}-\mathrm{NMR}(75$ $\left.\mathrm{MHz}, \mathrm{CDCl}_{3}\right): \delta=18.7\left(\mathrm{CH}_{3}-4\right), 26.0\left(\mathrm{O}=\mathrm{C}-\mathrm{CH}_{3}\right), 48.2\left(\mathrm{C}-2^{\prime} / \mathrm{C}-6^{\prime}\right), 51.3\left(\mathrm{~d}, J=3.2 \mathrm{~Hz}, \mathrm{C}-3^{\prime} / \mathrm{C}-5^{\prime}\right)$, $101.5(\mathrm{C}-8), 110.7$ (C-6), 112.2 (C-3), $114.6(\mathrm{C}-4 \mathrm{a}), 116.3$ (d, $\left.{ }^{2} J_{\mathrm{C}-\mathrm{F}}=20.6 \mathrm{~Hz}, \mathrm{C}-3^{\prime \prime}\right), 119.2$ (d, $\left.{ }^{4} J_{\mathrm{C}-\mathrm{F}}=2.7 \mathrm{~Hz}, \mathrm{C}-5 "\right), 122.9\left(\mathrm{~d},{ }^{3} J_{\mathrm{C}-\mathrm{F}}=7.9 \mathrm{~Hz}, \mathrm{C}-4 "\right), 124.4\left(\mathrm{~d},{ }^{3} J_{\mathrm{C}-\mathrm{F}}=3.5 \mathrm{~Hz}, \mathrm{C}-6 "\right), 125.9(\mathrm{C}-5), 139.5$ $\left(\mathrm{d},{ }^{2} J_{\mathrm{C}-\mathrm{F}}=19.7 \mathrm{~Hz}, \mathrm{C}-1 "\right), 144.9(\mathrm{C}-4), 145.7$ (C-7), $152.4(-\mathrm{C}=\mathrm{N}), 155.3(\mathrm{C}-8 \mathrm{a}), 155.9$ (d, ${ }^{1} J_{\mathrm{C}-\mathrm{F}}=245 \mathrm{~Hz}$, C-2"), 161.2 (C-2), 195.1 (O=C-Me). Anal. Calcd. for $\mathrm{C}_{23} \mathrm{H}_{23} \mathrm{FN}_{4} \mathrm{O}_{3}(422.45 \mathrm{~g} / \mathrm{mol})$ : C, 65.39; H, 5.49; N, 13.26. Found: C, 65.18; H, 5.40; N, 13.15. ESI-HRMS m/z: Calcd. for $\mathrm{C}_{23} \mathrm{H}_{22} \mathrm{FN}_{4} \mathrm{O}_{3}[\mathrm{M}-\mathrm{H}]^{-}$ 421.16759. Found: 421.16814.

7-\{2-[1-(4-(4-Fluorophenyl)piperazin-1-yl)-2-oxopropylidene]hydrazinyl\}-4-methyl-2H-chromen-2-one (3l): Yield $=0.45 \mathrm{~g}(59.3 \%) ; \mathrm{Mp}=271-273{ }^{\circ} \mathrm{C} .{ }^{1} \mathrm{H}-\mathrm{NMR}\left(300 \mathrm{MHz}, \mathrm{CDCl}_{3}\right): \delta=2.40\left(\mathrm{~d}, J=1.0 \mathrm{~Hz}, 3 \mathrm{H}, \mathrm{CH}_{3^{-}}\right.$ 4), 2.45 (s, 3H, O=C-CH $), 3.21\left(\mathrm{~m}, 4 \mathrm{H}, \mathrm{H}_{2}-3^{\prime}+\mathrm{H}_{2}-5^{\prime}\right), 3.22\left(\mathrm{~m}, 4 \mathrm{H}, \mathrm{H}_{2}-2^{\prime}+\mathrm{H}_{2}-6^{\prime}\right), 6.14(\mathrm{~d}, J=1.0$ Hz, 1H, H-3), 6.89-6.98 (m, 4H, H-2" + H-3" + H-5" + H-6"), 7.03 (dd, J = 8.7 Hz, 2.1 Hz, 1H, H-6), $7.18(\mathrm{~d}, J=2.1 \mathrm{~Hz}, 1 \mathrm{H}, \mathrm{H}-8), 7.51$ (d, $J=8.7 \mathrm{~Hz}, 1 \mathrm{H}, \mathrm{H}-5), 9.24$ (s, 1H, N-H). ${ }^{13} \mathrm{C}-\mathrm{NMR}(75 \mathrm{MHz}$, $\left.\mathrm{CDCl}_{3}\right): \delta=18.7\left(\mathrm{CH}_{3}-4\right), 26.0\left(\mathrm{O}=\mathrm{C}-\mathrm{CH}_{3}\right), 48.2\left(\mathrm{C}^{\prime} 2^{\prime} / \mathrm{C}-6^{\prime}\right), 51.3\left(\mathrm{C}-3^{\prime} / \mathrm{C}-5{ }^{\prime}\right), 101.6(\mathrm{C}-8), 110.7(\mathrm{C}-$ 6), 112.2 (C-3), 114.7 (C-4a), 115.7 (d, $\left.{ }^{2} J_{\mathrm{C}-\mathrm{F}}=22 \mathrm{~Hz}, \mathrm{C}-3 " / \mathrm{C}-5 "\right), 118.3\left(\mathrm{~d},{ }^{3} J_{\mathrm{C}-\mathrm{F}}=7.7 \mathrm{~Hz}\right.$, C-2"/C-6"), 157.2 (d, $\left.{ }^{1} J_{\mathrm{C}-\mathrm{F}}=240 \mathrm{~Hz}, \mathrm{C}-4 "\right), 125.9$ (C-5), $147.3\left(\mathrm{~d},{ }^{4} J_{\mathrm{C}-\mathrm{F}}=2.2 \mathrm{~Hz}, \mathrm{C}-1 "\right), 144.8(\mathrm{C}-4)$, 145.6 (C-7), $152.5(-\mathrm{C}=\mathrm{N}), 155.3$ (C-8a), $161.2(\mathrm{C}-2), 195.2(\mathrm{O}=\mathrm{C}-\mathrm{Me})$. Anal. Calcd. for $\mathrm{C}_{23} \mathrm{H}_{23} \mathrm{FN}_{4} \mathrm{O}_{3}$ (422.45 g/mol): C, 65.39; H, 5.49; N, 13.26. Found: C, 65.22; H, 5.45; N, 13.18. ESI-HRMS m/z: Calcd. for $\mathrm{C}_{23} \mathrm{H}_{24} \mathrm{FN}_{4} \mathrm{O}_{3}[\mathrm{M}+\mathrm{H}]^{+}$423.18324. Found: 423.18270 .

4-Methyl-7-(2-(2-oxo-1-(4-(pyrimidin-2-yl)piperazin-1-yl)propylidene)hydrazinyl)-2H-chromen-2-one (3m): Yield $=0.55 \mathrm{~g}(75.2 \%) ; \mathrm{Mp}=236-238{ }^{\circ} \mathrm{C} .{ }^{1} \mathrm{H}-\mathrm{NMR}\left(300 \mathrm{MHz}, \mathrm{CDCl}_{3}\right): \delta=2.39(\mathrm{~d}, J=1.0 \mathrm{~Hz}$, $\left.3 \mathrm{H}, \mathrm{CH}_{3}-4\right), 2.43$ (s, 3H, O=C-CH $), 3.12\left(\mathrm{~m}, 4 \mathrm{H}, \mathrm{H}_{2}-3^{\prime}+\mathrm{H}_{2}-5^{\prime}\right), 3.94$ (m, 4H, $\left.\mathrm{H}_{2}-2^{\prime}+\mathrm{H}_{2}-6^{\prime}\right), 6.12$ (d, $J=1.0 \mathrm{~Hz}, 1 \mathrm{H}, \mathrm{H}-3), 6.52(\mathrm{t}, J=4.8 \mathrm{~Hz}, 1 \mathrm{H}, \mathrm{H}-5 "), 7.06(\mathrm{dd}, J=8.7,2.0 \mathrm{~Hz}, 1 \mathrm{H}, \mathrm{H}-6), 7.20(\mathrm{~d}$, $J=2.0 \mathrm{~Hz}, 1 \mathrm{H}, \mathrm{H}-8), 7.52$ (d, $J=8.7 \mathrm{~Hz}, 1 \mathrm{H}, \mathrm{H}-5), 8.32$ (d, $J=4.8 \mathrm{~Hz}, 2 \mathrm{H}, \mathrm{H}-4 "+\mathrm{H}-6 "), 9.35$ (s, 1H, $\mathrm{N}-\mathrm{H}) .{ }^{13} \mathrm{C}-\mathrm{NMR}\left(75 \mathrm{MHz}, \mathrm{CDCl}_{3}\right): \delta=18.7\left(\mathrm{CH}_{3}-4\right), 26.0\left(\mathrm{O}=\mathrm{C}-\mathrm{CH}_{3}\right), 44.4\left(\mathrm{C}-2^{\prime} / \mathrm{C}-6^{\prime}\right), 47.9$ (C-3'/C-5'), 101.6 (C-8), 110.3 (C-5"), 110.8 (C-6), 112.2 (C-3), 114.7 (C-4a), 125.9 (C-5), 144.8 (C-4), 145.7 (C-7), $152.5(-\mathrm{C}=\mathrm{N}), 155.3$ (C-8a), 157.8 (C-4" + C-6"), 159.8 (C-2"), 161.2 (C-2), 195.2 $(\mathrm{O}=\mathrm{C}-\mathrm{Me})$. Anal. Calcd. for $\mathrm{C}_{21} \mathrm{H}_{22} \mathrm{~N}_{6} \mathrm{O}_{3}(406.44 \mathrm{~g} / \mathrm{mol})$ : $\mathrm{C}, 62.06 ; \mathrm{H}, 5.46 ; \mathrm{N}, 20.68$. Found: $\mathrm{C}, 61.87$; $\mathrm{H}, 5.38$; N, 20.52. ESI-HRMS m/z: Calcd. for $\mathrm{C}_{21} \mathrm{H}_{21} \mathrm{~N}_{6} \mathrm{O}_{3}[\mathrm{M}-\mathrm{H}]^{-}$405.16751. Found: 405.16696.

7-\{2-[1-(4-(1-benzyl-2-ethyl-4-nitro-1H-imidazol-5-yl)piperazin-1-yl)-2-oxopropylidene] hydrazinyl\}4-methyl-2H-chromen-2-one (3n): Yield $=0.89 \mathrm{~g}$ (88.7\%); $\mathrm{Mp}=193-195{ }^{\circ} \mathrm{C} .{ }^{1} \mathrm{H}-\mathrm{NMR}(300 \mathrm{MHz}$, $\left.\mathrm{CDCl}_{3}\right): \delta=1.28\left(\mathrm{t}, J=7.5 \mathrm{~Hz}, 3 \mathrm{H}, \mathrm{CH}_{2}-\mathrm{CH}_{3}\right), 2.39$ (d, $\left.J=1.0 \mathrm{~Hz}, 3 \mathrm{H}, \mathrm{CH}_{3}-4\right), 2.41(\mathrm{~s}, 3 \mathrm{H}$, 
$\left.\mathrm{O}=\mathrm{C}-\mathrm{CH}_{3}\right), 2.61\left(\mathrm{q}, J=7.5 \mathrm{~Hz}, 2 \mathrm{H}, \mathrm{CH}_{2}-\mathrm{Me}\right), 2.68\left(\mathrm{~m}, 4 \mathrm{H}, \mathrm{H}_{2}-3^{\prime}+\mathrm{H}_{2}-5^{\prime}\right), 3.36\left(\mathrm{~m}, 4 \mathrm{H}, \mathrm{H}_{2}-2^{\prime}+\mathrm{H}_{2}-6^{\prime}\right)$, $5.17\left(\mathrm{~s}, 2 \mathrm{H}, \mathrm{CH}_{2}-\mathrm{Ph}\right), 6.12(\mathrm{~d}, J=1.0 \mathrm{~Hz}, 1 \mathrm{H}, \mathrm{H}-3), 7.00$ (dd, J=8.7 Hz, 2.0 Hz, 1H, H-6), 7.02 (d, $J$ = 7.5 Hz, 2H, H-2"'/ H-6'"), 7.30 (d, J = 2.0 Hz, 1H, H-8), 7.32-7.37 (m, 3H, H-3"' + H-4"' + H-5"'), $7.51(\mathrm{~d}, J=8.7 \mathrm{~Hz}, 1 \mathrm{H}, \mathrm{H}-5), 9.34(\mathrm{~s}, 1 \mathrm{H}, \mathrm{N}-\mathrm{H}) .{ }^{13} \mathrm{C}-\mathrm{NMR}\left(75 \mathrm{MHz}, \mathrm{CDCl}_{3}\right): \delta=11.3\left(-\mathrm{CH}_{2}-\mathrm{CH}_{3}\right)$, $18.8\left(\mathrm{CH}_{3}-4\right), 21.2\left(-\mathrm{CH}_{2}-\mathrm{Me}\right), 25.9\left(\mathrm{O}=\mathrm{C}-\mathrm{CH}_{3}\right), 46.2\left(\mathrm{CH}_{2}-\mathrm{Ph}\right), 48.4\left(\mathrm{C}-2^{\prime} / \mathrm{C}-6^{\prime}\right), 49.6\left(\mathrm{C}-3^{\prime} / \mathrm{C}-5^{\prime}\right)$, 101.6 (C-8), 111.1 (C-6), 112.2 (C-3), 114.8 (C-4a), 125.9 (C-5), 126.0 (C-2"'/C-6"'), 128.3 (C-4"'), 129.3 (C-3"'/C-5"'), 135.4 (C-1"'), 139.1 (C-1"), 140.0 (C-5"), 144.5 (C-4), 145.3 (C-4"), 145.5 (C-7), $152.5($ Ac- $C=N), 155.3$ (C-8a), $161.3(\mathrm{C}-2), 195.4(\mathrm{O}=C-\mathrm{Me})$. Anal. Calcd. for $\mathrm{C}_{29} \mathrm{H}_{31} \mathrm{~N}_{7} \mathrm{O}_{5}(557.60$ g/mol): C, 62.47; H, 5.60; N, 17.58. Found: C, 62.54; H, 5.64; N, 17.42. ESI-HRMS m/z: Calcd. for $\mathrm{C}_{29} \mathrm{H}_{31} \mathrm{~N}_{7} \mathrm{NaO}_{5}[\mathrm{M}+\mathrm{Na}]^{+}$580.22844. Found: 580.22789.

\subsection{Cell Lines and Cell Culture}

Materials and Methods

Human breast cancer cell line MCF-7, was a gift from Drs. Prakash and Mitzi Nagarkatti (University of South Carolina, School of Medicine, Columbia, SC, USA). Human leukemia HL-60-Acute Myelocytic Leukemia (AML) and K5626 were gifts from Salem Akel at Hashemite University, Zarqa, Jordan. The three cell lines were maintained in complete RPMI-1640 medium supplemented with $10 \%$ heat-inactivated fetal bovine serum, $2 \mathrm{mM}$ L-glutamine, 100 units $/ \mathrm{mL}$ penicillin, $100 \mu \mathrm{g} / \mathrm{mL}$ streptomycin (all from Gibco), $50 \mu \mathrm{M}$ 2-mercaptoethanol (Research Organics, USA), $10 \mathrm{mM}$ HEPES buffer (AppliChem, Germany), and gentamicin sulfate at $0.05 \mathrm{mg} / \mathrm{mL}$. Cells were maintained under standard culture conditions at $37{ }^{\circ} \mathrm{C}$ in a water-saturated atmosphere of $5 \%$ $\mathrm{CO}_{2}$ in air. ZR-75-1 breast cancer cells (obtained from ATCC) were cultured in DMEM supplemented with $2 \mathrm{mM}$ glutamine and 10\% Fetal Bovine Serum (FBS, Gibco Life Technologies).

\subsubsection{Cell Proliferation Assay}

MCF-7 and K562 cells were seeded at a density of $1 \times 10^{4}$ and $4 \times 10^{4}$ per well in 96-well plates in appropriate medium, then treated with $50 \mu \mathrm{M}$ concentrations of the tested compounds. For the $\mathrm{IC}_{50}$ determination, the cells were treated with increasing concentrations of the tested compound $(1.56-100 \mu \mathrm{M})$. In all assays, the drugs were dissolved in DMSO immediately before the addition to cell cultures and equal amounts of the solvent were added to control cells; the final concentration of DMSO did not exceed 1\%. Cell viability was assessed, after 3 days of treatment, with tetrazolium dye 3-(4,5-dimethylthiazol-2-yl)-2,5-diphenyltetrazolium bromide (MTT), obtained from Sigma (Dorset, UK). IC $_{50}$ concentrations were obtained from the dose-response curves using Graph Pad Prism Software 5 (San Diego, CA, USA, www.graphpad.com), and doxorubicin as positive control.

\section{Acknowledgements}

We wish to thank the Deanship of Scientific Research at the University of Jordan, Amman, Jordan, for financial support. 


\section{References and Notes}

1. Abdel-Jalil, R.J.; El Momani, E.Q.; Hamad, M.; Voelter, W.; Mubarak, M.S.; Smith, B.H.; Peters, D.G. Synthesis, antitumor activity, and electrochemical behavior of some piperazinyl amidrazones. Monatsh. Chem. 2010, 141, 251-258, and references cited therein.

2. Tollefson, G.D.; Lancaster, S.P.; Montague-Clouse, J. The association of buspirone and its metabolite 1-pyrimidinylpiperazine in the remission of comorbid anxiety with depressive features and alcohol dependency. Psychopharmacol. Bull. 1991, 27, 163-170.

3. Rotzinger, S.; Fang, J.; Baker, G.B. Trazodone is metabolized to m-chlorophenyl-piperazine by CYP3A4 from human sources. Drug Metab. Dispos. 1998, 26, 572-575.

4. Oh, Y.S.; Yun, M.; Hwang, S.Y.; Hong, S.; Shin, Y.; Lee, K.; Yoon, K.H.; Yoo, Y.J.; Kim, D.S.; Lee, S.H.; et al. Discovery of LB30057, a benzamidrazone-based selective oral thrombin inhibitor. Bioorg. Med. Chem. Lett. 1998, 8, 631-634.

5. Lee, K.; Hwang, S.Y.; Hong, S.; Hong, C.Y.; Lee, C.-S.; Shin, Y.; Kim, S.; Yun, M.; Yoo, Y.J.; Kang, M.; et al. Structural modification of an orally active thrombin inhibitor, LB30057: replacement of the D-pocket-binding naphthyl moiety. Bioorg. Med. Chem. 1998, 6, 869-876.

6. Lee, K.; Jung, W.-H.; Park, C.W.; Park, H.D.; Lee, S.H.; Kwon, O.H. Noncovalent tripeptidic thrombin inhibitors incorporating amidrazone, amine and amidine functions at P1. Bioorg. Med. Chem. Lett. 2002, 12, 1017-1022.

7. Clemens, F.; Drutkowski, G.; Wiese, M.; Frohberg, P. The inactivation of lipoxygenase-1 from soybeans by amidrazones. Biochim. Biophys. Acta 2001, 1549, 88-98.

8. Murray, R.D.H.; Mendenz, J.; Bouwn, S.A. The Natural Coumarins; Wiley \& Sons: New York, NY, USA, 1982.

9. Schonberg, A.; Latif, N. Furochromones and coumarins. XI. The molluscicidal activity of bergapten, isopimpinellin, and xanthotoxin. J. Am. Chem. Soc. 1954, 76, 6208.

10. Mitra, A.K.; Misra, S.K.; Patra, A. New synthesis of 3-alkyl coumarins. Synth. Commun. 1980, 10, 915-919.

11. Sardari, S.; Mori, Y.; Horita, K.; Micetich, R.G.; Nishibe, S.; Daneshtalab, M. Synthesis and antifungal activity of coumarins and angular furanocoumarins. Bioorg. Med. Chem. 1999, 7, 1933-1940.

12. Khan, M.S.Y.; Sharma, P. Synthesis of new $\alpha$-pyronoflavones and related products. Part II. Indian J. Chem. 1993, 32, 817-821.

13. Xie, L.; Takeuchi, Y.; Cosentino, L.M.; MacPhail, A.T.; Lee, H.K. Anti-AIDS agents. 42. Synthesis and anti-HIV activity of disubstituted (3'R,4'R)-3',4'-di-O-(S)-camphanoyl-(+)-ciskhellactone analogues. J. Med. Chem. 2001, 44, 664-671.

14. Singer, L.A.; Kong, N.P. Vinyl radicals. Stereoselectivity in hydrogen atom transfer to equilibrated isomeric vinyl radicals. J. Am. Chem. Soc. 1966, 88, 5213-5219.

15. O'Kennedy, R.; Thornes, R.D. Coumarins: Biology, Application and Mode of Action; Wiley \& Sons: Chichester, UK, 1997.

16. Zahradnik, M. The Production and Application of Florescent Brightening Agents; Wiley \& Sons: New York, NY, USA, 1992. 
17. Brzozowski, Z.; Saczewski, F.; Slawinski, J.; Bednarski, P.; Grunert, R.; Gdaniec, M. Synthesis, structural characterization, and in vitro antitumor activity of novel N-(6-chloro-1,1-dioxo-1,4,2benzodithiazin-3-yl)arylsulfonamides. Bioorg. Med. Chem. 2007, 15, 2560-2572.

18. Burbuliene, M.M.; Maldutyte, E.; Vainilavicius, P. Synthesis of S- and O-alkanoic acid derivatives of 6-phenyl-2-sulfanyl-4(3H)-pyrimidinone. Chemija. 2005, 16, 39-42.

19. Kontogiorgis, C.; Hadjipavlou-Litina, D. Biological evaluation of several coumarin derivatives designed as possible anti-inflammatory/antioxidant agents. J. Enz. Inhib. Med. Chem. 2003, 18, 63-69.

20. Satyanarayana, V.S.V.; Sreevani, P.; Sivakumar, A.; Vijayakumar, V. Synthesis and antimicrobial activity of new Schiff bases containing coumarin moiety and their spectral characterization. ARKIVOC 2008, 17, 221-233.

21. Al-Zghoul, K.H.A.; Salih, K.S.M.; Ayoub, M.T.; Mubarak, M.S. A convenient procedure for the synthesis of substituted 4-methylaminocoumarins. Heterocycles 2005, 65, 2937-2947.

22. Al-Soud, Y.A.; Al-Sa'doni, H.H.; Amajaour, H.A.S.; Salih, K.S.M.; Mubarak, M.S.; Al-Masoudi, N.A.; Jaber, I.H. Synthesis, characterization and anti-HIV and antitumor activities of new coumarin derivatives. Z. Naturforsch. 2008, 63b, 83-89.

23. Salih, K.S.M.; Ayoub, M.T.; Saadeh, H.A.; Al-Masoudi, N.A.; Mubarak, M.S. Synthesis, characterization, and biological activities of new benzofuran derivatives. Hetrocycles 2007, 71, 1577-1587.

24. Al-Rifai, A.A.; Ayoub, M.T.; Shakya, A.K.; Abu Safieh, K.A.; Mubarak, M.S. Synthesis, characterization, and antimicrobial activity of some new coumarin derivatives. Med. Chem. Res. 2011, 20, (in press).

25. Phillips, R.R. The Japp-Klingemann Reaction. Org. React. 1959, 10, 143-178.

26. Yao, H.-C.; Resnick, P. Azo-hydrazone conversion. I. The Japp-Klingemann reaction. J. Am. Chem. Soc. 1962, 84, 3514-3517.

27. Barrett, G.C.; El-Abadelah, M.M.; Hargreaves, M.K. Cleavage of 2-acetyl-2phenylazopropionanilide and related compounds by boron trifluoride. New Japp-Klingemann reactions. J. Chem. Soc. (C) 1970, 1986-1989.

28. Pozdnev, V.F. An improved method of synthesis of 7-amino-4-methylcoumarin. Khim. Geterotsikl. Soed. 1990, 3, 312-314.

29. Ronad, P.; Dharbamalla, S.; Hunshal, R.; Maddi, V. Synthesis of novel substituted 7-(benzylideneamino)-4-methyl-2H-chromen-2-one derivatives as anti-inflammatory and analgesic agents. Arch. Pharm. 2008, 341, 696-700.

30. Butler, R.N.; Scott, F.L. Versatile reactive intermediates: Hydrazidic halides. Chem. Ind. (London) 1970, 1216-1221.

31. Ulrich, H. The Chemistry of Imidoyl Halides; Plenum Press: New York, NY, USA, 1968; Chapter 7, pp. 174-192.

32. Hegarty, A.F.; Aylward, J.B.; Scott, F.L. Synthesis and rearrangement of hydrazidic azides. J. Chem. Soc. (C) 1967, 2587-2593.

33. Dalla Corce, P.; Del Buttero, P.; Licandro, E.; Maiorana, S. Synthesis of (arylazomethylene)triphenylphosphoranes from arylhydrazonoyl chlorides (via nitrilimines in situ) and triphenylphosphine. Synthesis 1979, 299-300. 
34. Heubach, G. Synthesis of new 2,5-dihydro-1,2,3,5-thiatriazole 1-oxides and 3,4-dihydro-2H1,2,4,3-triazaphosphole 3-oxides. Liebigs. Ann. Chem. 1980, 1980, 1376-1383.

35. Hassaneen, H.M.; Mousa, H.A.H.; Abed, N.M. Chemistry of C-heteroarylhydrazidoyl halides. Synthesis and reactions of N-(p-nitrophenyl)-C-(2-thienyl)formohydrazidoyl halides. Heterocycles 1988, 27, 695-706.

36. Benincori, T.; Sannicoló, F. New access to 2-(arylazo)-, 2-(arylhydrazo)-, and 2-aminoindoles, benzofurans, and -thianaphthenes. J. Org. Chem. 1988, 53, 1309-1312.

37. Galishev, V.A.; Chistokletov, V.N.; Petrov, A.A. 1,3-Dipolar addition to unsaturated compounds. XXXIV. Reactions of diphenylmethyleneaminodiphenylphosphine with nitrilimines. Zh. Obshch. Khim. 1975, 45, 1695-1697.

38. Shawali, A.S.; Párkányi, C. Hydrazidoyl halides in the synthesis of heterocycles. J. Heterocycl. Chem. 1980, 17, 833-854.

39. Al-Soud, Y.A.; Al-Sa'doni, H.; Amajaour, H.A.S.; Al-Masoudi, N.A. Nitroimidazoles. Part 3. Synthesis and anti-HIV activity of new N-alkyl-4-nitroimidazoles bearing benzothiazole and benzoxazole backbones. Z. Naturforsch. 2007, 62, 523-528.

Sample availability: Contact the authors.

(C) 2011 by the authors; licensee MDPI, Basel, Switzerland. This article is an open access article distributed under the terms and conditions of the Creative Commons Attribution license (http://creativecommons.org/licenses/by/3.0/). 